\title{
Innovative teaching and learning programmes from the CDRC
}

\author{
Felix M. Bivens
}

\section{Context}

The Citizenship Development Research Consortium (CDRC) is a UK Department for the International Development-funded group of university- and NGO-based researchers working together for almost a decade, examining concepts and practices of citizenship in diverse contexts across the globe. Much of the research carried out by this collective falls within the PAR and CBR traditions, involving collaborations between university academics and those active in communities and civil society organizations. The group has produced numerous publications and papers, including a seven-volume set of collected case studies. As the project moves into its final phases, participants are looking to understand how this body of learning and knowledge can be brought effectively into university curricula and into the classroom. In January 2008, the CDRC formed a teaching and learning group which has been experimenting with various ways in which citizenship can be taught within a formal university curricula and a traditional classroom setting.

One of the main lessons learned from the group is that content and process are equally important when talking about issues of citizenship and democracy. Although case studies are important for helping students understand the many different ways in which ideas of citizenship are lived out in different contexts and political environments, ultimately there should also be space to act out and experiment with democratic processes and power relations in the classroom itself.

The following examples lay out briefly how the work of the CDRC is impacting university curricula and pedagogy across a global selection of HEIs - and one NGO.

\section{University of Alberta, Canada - democratic citizenship: participation, deliberation and power}

This political science course was structured with a highly participatory pedagogy. The convener used minimal lecturing, devoting most class time to discussion. The majority of the class meetings were led by the students themselves who made generative conceptual presentations, then facilitated a discussion involving participatory. As course convener David Kahane wrote in the course syllabus, 'This is a genuine seminar, which is to say an equal conversation involving all of us.' 
Kahane found his CDRC course a challenging experiment in terms of content and pedagogy. While students were genuinely interested in the case studies pulled from the CDRC work, often they did not have enough contextual knowledge to fully grasp the details of what they were studying. To address this point, Kahane envisions taking on fewer cases in future iterations and spending more time fleshing out the cultural and political environment surrounding the data in the case study. Fortunately, the CDRC has a significant online archive of supplemental materials and grey literature that contributed to the final published pieces that students could access. Pedagogically, Kahane found a fair amount of resistance and trepidation amongst the students. They were not sure what to make of the idea of a democratic classroom and were often unwilling to challenge the traditional power relationships of the classroom. He found that this process improved over the course of the semester as students grew more confident and trusting of the space and freedoms he offered.

\section{University of the Western Cape, South Africa - governance, administration and ethics}

This course also drew heavily on CDRC materials. A major difference was that the course was structured as an intensive block session - forty hours of contact time in a single week. As in the previous case, the course convener met resistance in trying to engage students in a more participatory and co-constructed pedagogical approach. Given the course's particularly short time-span, there was little opportunity to build an environment of trust where students were willing to push their limits and try new things. Many of the students in the course were from disadvantaged backgrounds and had difficulty with the academic language of the CDRC case studies and were often frustrated in not seeing the relevance of the studies to their own situations. Occasionally, some participatory exercises were successful in engaging the students in genuine, passionate conversations. In one such exercise, students reconstructed the physical arrangement of the classroom - furniture and people - in order to create a more democratic and cooperative space. However, on the whole, students did not wish to diverge from the course syllabus in a significant way because all courses at UWC are externally examined; the students feared any departure from the 'expected/prescribed content irrespective of class context or decisions' (Williams, 2009, p. 8).

\section{University of Toronto, Canada - citizenship, political participation and social change in the global South}

As in the previous examples, this course mainly used CDRC case studies as core literature. While these students - primarily white Canadians - sometimes had difficulty with the contextual details of the Southern-based cases, the course convener found a very practical aid to help students better engage with the research. Because members of the CDRC had formed close personal ties during their years of working together, this instructor contacted her CDRC peers whose research 
she had included in the course syllabus and asked them to make short videos of themselves discussing the background, experience and impact of their case's CBR. Being able to see and hear the research of authors on screen made the cases more accessible for students. As in the University of Alberta example, the students were given responsibility for designing and facilitating many of the classroom activities. This resulted in students devising many innovative exercises which helped to deepen and 'experientialize' the theoretical and conceptual dimensions of the course. One such activity assessed the power dynamics of physical meeting spaces on campus. The student facilitator relocated the discussion multiple times during the same class meeting, from the classroom to an outdoor park area, to a student cafeteria, to a campus library and finally to the dean's conference room. Students and the convener reflected on how the environment shaped their ongoing discussion and emotional reactions (von Lieres, 2009).

\section{PRIA continuing education, India - online certificate in international perspectives on citizenship, democracy and accountability (MA in participatory development)}

Not all members of the CRDC are university researchers. The Indian NGO in Participatory Research in Asia (PRIA) has been one of the core institutional members of the group. PRIA has been an influential pioneer in PAR and CBR in the global South. Although PRIA frequently engages with academics and universities from across the globe, its main focus is in collaborating with community groups and civil society organizations. They aim to help organizations to develop capacity to carry out participatory research and assessments and to move generally into methods of participatory development. As PRIA grew, it developed its continuing education centre for more intensively sharing its learning and innovations in participatory methods. Most of this training had been done on-site at the PRIA campus or in regional workshops. However, as part of the CDRC Teaching and Learning initiative, PRIA set out to develop new distance education offerings through which they could involve students from all over the world. PCE has already created and facilitated a three-month online postgraduate certificate in international perspectives on citizenship, democracy and accountability. Here again the core of the course materials was drawn from the CDRC body of work. The targeted students were civil society practitioners, government staff, policymakers and academics. In October 2008, the first iteration of the course launched with nineteen students. PRIA has designed a two-year MA in participatory development which includes a year of intensive coursework and a year of PAR fieldwork. 